\title{
Use of probiotics in atopic dermatitis
}

Michelle Lise

Isis Mayer ${ }^{1}$

Mauricio Silveira ${ }^{2}$

1. Pontifícia Universidade Católica do Rio Grande do Sul, Dermatology, Porto Alegre, RS, Brasil. 2. Doctor of Private Practice, Porto Alegre, RS, Brasil.

http://dx.doi.org/10.1590/1806-9282.64.11.997

\section{SUMMARY}

Atopic dermatitis is a common skin disease. Its increased incidence has changed the focus of research on atopic dermatitis toward epidemiology, prevention, and treatment. Evidence suggests that intestinal microbiota plays an important role in the pathogenesis of atopic dermatitis inducing immunosuppression, but its exact mechanism is still unclear. Probiotics have been widely reported to act on the immune system. They are living microorganisms with immunomodulatory effects that stimulate Th1 cytokines and suppress the Th2 response, which are being researched for the treatment of several diseases. Probiotics most commonly used are part of the intestinal microflora like lactobacilli, bifidobacteria, and enterococci. We describe here a case of evident response to the use of probiotics in a girl with severe atopic dermatitis, with a significant change in severity scores of atopic dermatitis (BSA/SCORAD/FDLQI). Modulation of the intestinal microbiota with probiotics may offer a way to prevent or treat allergic diseases, including atopic dermatitis.

KEYWORDS: Allerg. Atopic dermatitis. Inflammation. Intestinal microbiota. Probiotics.

\section{INTRODUCTION}

About a century ago, Metchnikoff first hypothesized that some intestinal bacteria "produce compounds useful against premature aging”. Since then, studies progressed, leading to a remarkable improvement of the knowledge about the role of intestinal micro-organisms ${ }^{1}$, in several areas of medicine. Many studies on the pathogenesis of allergy continue to show the importance of commensal gastrointestinal tract bacteria in the stimulation and targeting of the immune system².

The gut of newborns is sterile and is gradually colonized by environmental bacteria. There is a known difference between children born of vaginal delivery and cesarean section. In the cesarean section, there is a delay in the colonization of bifidobacteria, lactobacilli, and bacterioids in the gut. After this initial colonization phase, the type of feeding will influence the maintenance of the flora, so breastfed children will have higher growth and activity of bifidobacteria and lactobacillus than those fed with formula ${ }^{2}$.

There is an increasing number of children with allergies; in 1950 the prevalence of allergic symptoms in developed countries was $5 \%$ and now is about $40 \%{ }^{2}$. Epidemiological studies show that a higher incidence of gastrointestinal tract infections is associated with a lower prevalence of allergies ${ }^{2}$. A defect in the early stimulation of TH1 cells is related to the development of allergic diseases ${ }^{2}$.

Atopic dermatitis (AD) is one of the most common chronic inflammatory skin diseases, and its prevalence is also growing ${ }^{3-5}$. 
There is a known genetic cause for $\mathrm{AD}$, but it alone does not explain this increasing prevalence ${ }^{5}$. $\mathrm{So}, \mathrm{AD}$ is considered a multifactorial disease with genetic, epigenetic, developmental and environmental factors associated with its presentation ${ }^{5}$.

A mechanism involved in the pathogenesis of $\mathrm{AD}$ is the decrease in regulatory $\mathrm{T}$ cells (Treg), which are crucial regulators of the immune response ${ }^{6}$. It is already known that an imbalance in the activation of TH1/TH2 cytokines is implicated in the development of $\mathrm{AD}^{6}$ and, increasing evidence suggests that intestinal microbiota play an important role in immune system regulation ${ }^{7}$. Pathogenesis of $\mathrm{AD}$ is complex and microbial exposures early in life proved to be protective against it ${ }^{5}$. Knowing that differences in intestinal microbiota composition have been found in AD and have been implicated in its triggering ${ }^{4}$.

Another mechanism involved in AD is dysfunction in the skin barrier. Barrier defects in $\mathrm{AD}$ also seem to affect the intestinal mucosa, also the composition of the intestinal microflora is different in $\mathrm{AD}$ patients. In $\mathrm{AD}$ the barrier is impaired, not only in the skin but also in the intestinal mucosa, causing the transfer of exogenous antigens. In this matter, Lactobacillus paracasei was found to speed barrier function recovery ${ }^{6}$.

The use of probiotics has been researched for the treatment of several diseases, including in dermatology. However, the results of the studies have been controversial ${ }^{8}$.

Probiotics are live microorganisms with immunomodulatory effects and have a beneficial action on the hosts' health by changing immune response, competing with harmful gut flora, toxins, and host products, thus improving gut barrier function ${ }^{5}$.

The most commonly used organisms are lactobacillus bifidobacterium and enterococci ${ }^{6}$, and it is known that each strain has a specific immunomodulatory function, producing pro and anti-inflammatory cytokines ${ }^{5}$.

Probiotics mimic Th1 cytokines and suppress the Th2 response ${ }^{8}$. They also act on Tregs, which regulates the immune response, showing an inversely correlated level with immunoglobulin E (IgE), eosinophilia, and interferon-gamma $(\mathrm{IFN}-\gamma)^{6}$, so Tregs diminishes the inflammatory pathway. Also, some of them demonstrated the ability to accelerate the recovery of the skin barrier function ${ }^{6}$.

What is expected is that if the colonies of probiotics administered successfully colonize the gut, the flora change could modulate the immune response both locally and systemically ${ }^{5}$.

We report the use of probiotics in a patient with severe $\mathrm{AD}$ with excellent response.

\section{CASE}

Female patient, phototype two, 18 months of age, brought by the father, who related a previous history of classic atopic dermatitis with occasional cheilitis. Also referred episodes of wheezing and rhinorrhea started 8 months before, after hospitalization for adenovirus-related bronchiolitis.

She had already consulted with several dermatologists, had been using emollient after bath and mometasone cream two times a day on the lesions.

Physical examination showed xerosis, Dennie-Morgan double fold and areas of erythema and lichenification in the antecubital fossae (Figure 1), abdomen (Figure 2) and legs. Scoring atopic dermatitis index (SCORAD) was $60.15^{3}$, Body surface area (BSA) with lesions was 60\% and Family Dermatology Life Quality Index (FDLQI) was 18. IgE was 140 kU/L (normal $<60 \mathrm{kU} / \mathrm{L}$ ).

Treatment with probiotics (Bifidobacterium lactis HNO19, Lactobacillus acidophilus NCFM, Lactobacillus rhamnosus HNOO1, Lactobacillus paracasei LPC37) once a day was started with the maintenance of mometasone once a day and moisturizer after the bath. The patient returned after 2 weeks with significant improvement of the lesions (Figure 3). Physical exam showed no areas of erythema and complete resolution of the lesions. SCORAD was 4.95, BSA was $5 \%$, and FDLQI was 8 . The girl remains in follow-up, using probiotics for 12 months, maintaining the clinical improvement.

\section{DISCUSSION}

Atopic dermatitis is an immune disorder that is becoming increasingly prevalent throughout the world $^{3,4}$. It is a common, chronic, and refractory skin disease that manifests as eczema and pruritus with repeated exacerbations and regressions. The exact etiology of this disease remains unknown, and a cure is not currently available ${ }^{3,4}$. A lot has been said now about the hygiene hypothesis in the origin of DA and allergic diseases ${ }^{5}$.

Healthy gut flora includes more than 400 spe$\mathrm{cies}^{5}$, and various non-pathogenic microorganisms 
FIGURE 1: LICHENIFIED PLAQUES WHIT ERYTHEMA IN THE ANTECUBITAL FOSSAE

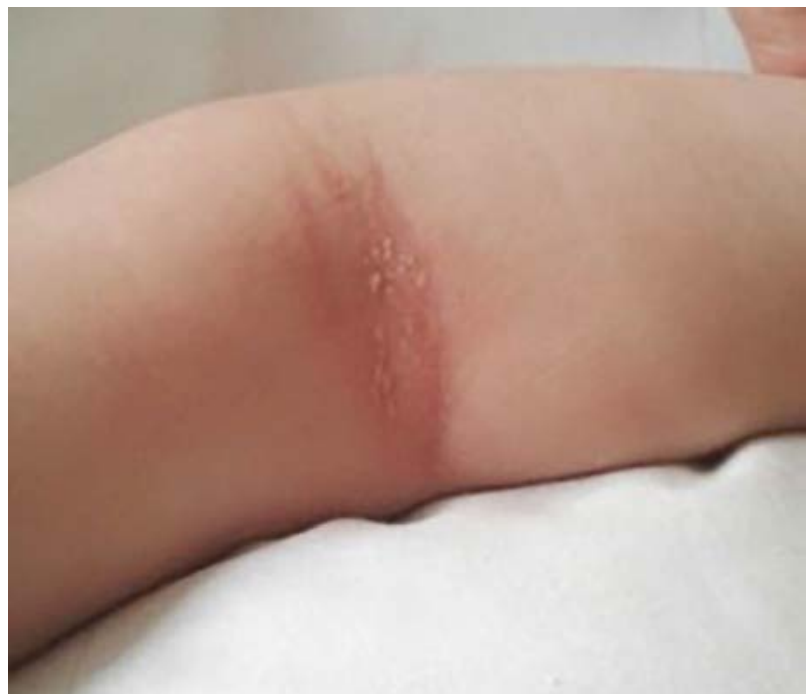

FIGURE 2: ERYTHEMATOUS PLAQUES IN THE ABDOMEN

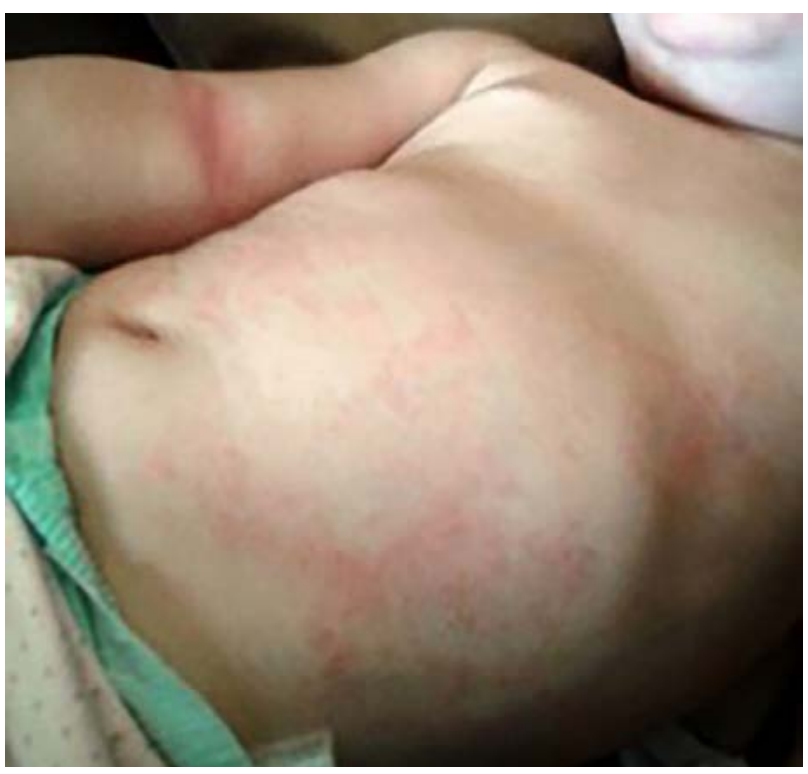

FIGURE 3: SKIN AFTER TREATMENT

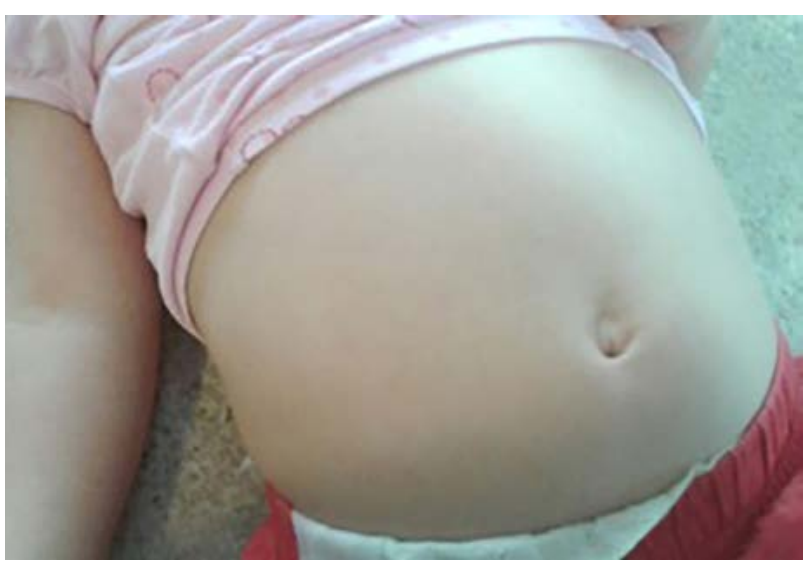

lead to the establishment of protective immunity against allergic disorders as the intestinal immune system comprises the most substantial portion of the overall immune system and remains exposed to intestinal bacteria ${ }^{8}$.

The stimulation by commensal bacteria of the gut during the early life is essential for the targeting of regulatory cells ${ }^{2}$. Infants with $\mathrm{AD}$ or other allergic diseases show less frequent intestinal colonization by Lactobacillus or Bifidobacterium, which is expected in healthy individuals, and more by Clostridium or Staphylococcus when compared to non-allergic infants ${ }^{5}$.

The use of substances that acts in this path of the immune system is of great interest. Pro and prebiotics do this.

Prebiotics are non-digestible substances that benefit the host by selectively stimulating the growth or activity of a specific group of intestinal bacteria ${ }^{2}$.

Probiotics are defined as non-digestible oligosaccharides, live microbial food supplements that provide benefits when administered in adequate way ${ }^{8}$. They selectively stimulate the growth of certain bacteria in the large intestine, thus producing a probiotic effect ${ }^{6}$.

Probiotics are useful in balancing gut microecology, restoring intestinal permeability, improving immunological gut barrier function and diminishing pro-inflammatory cytokines production ${ }^{8}$. They selectively stimulate the growth of certain bacteria in the large intestine, improving the bioavailability of calcium, reducing the development of precancerous lesions in the colon and inflammation of the mucosa in various gastrointestinal disorders ${ }^{8}$.

Probiotics have been used for centuries and have demonstrated a very safe profile as they are widely used in premature infants to prevent necrotizing enterocolitis and in immunosuppressed patients and patients undergoing chemotherapy or radiation to prevent and treat diarrhea ${ }^{8}$.

Individual response to probiotics is determined by the probiotic strain and dose, by the person's genetic background, lifestyle, diet, and resident microbiota ${ }^{4}$. Also, different strains of probiotics act in different inflammatory mediators paths.

The use of probiotics in dermatology is still incipient. Its applicability in AD is an open topic with controversial results ${ }^{9}$. It is already known that exposure to certain microbes early in life may influence the development of atopy ${ }^{9}$, as exposure and lack of exposure to certain microorganisms during early childhood alter the immune status toward the develop- 
ment of allergic diseases ${ }^{10}$. Also, it has been observed that the gut microflora of atopic children presents a reduced neonatal bifidobacteria to clostridia ratio ${ }^{8}$.

Probiotics have already been used in several dermatological diseases ${ }^{8}$, including acne and $\mathrm{AD}$, however, whether probiotics have a therapeutic effect on $\mathrm{AD}$ is still in question ${ }^{4}$ as studies on the use of probiotics on $\mathrm{AD}$ are small and heterogeneous ${ }^{6}$.

Lee et al. ${ }^{11}$ say that there is good evidence for the use of probiotics in prevention but not yet in the treatment of AD. Pre and postnatal use may reduce up to $61 \%$ the development of pediatric atopic dermatitis (PAD).

Wang and Wang ${ }^{4}$ found that exposure to these organisms is an effective intervention to reduce the severity of $\mathrm{AD}$ and improve quality of life of patients, with an implication in measures of some serum cytokine levels, urine oxidative stress biomarker, and fecal microbiota. They found that probiotics suppresses the Th2 response and IL-4, IL-5, and IL-13 cytokines production, and increase IL-10 and TGF-b levels by inducing Treg cells function ${ }^{4}$. Also, the reaction to probiotics has been found in IgE-associated and non-IgE-associated $\mathrm{AD}^{4}$. It is known that these bacteria and their function persist at least 6 months after cessation of supplementation ${ }^{5}$.

Yang et al. ${ }^{5}$ made a double-blind, randomized trial with 100 children and found no statistical difference between the group who used probiotics and placebo. The study showed that there was intestinal colonization but not a different immune modulation between cases and controls. These authors say that studies do not reflect the real world exposure to probiotics species, the action of combined species and the effect of one probiotic over another ${ }^{5}$.

Research of Pandurur et al. ${ }^{12}$ found that probiotics seem to have a protective role in AD prevention if administered in pre and postnatal period in both general and allergic risk population. Administration of probiotics in early life may have a role in the prevention of atopic sensitization ${ }^{12}$, even though it seems to be more effective in severe cases of $\mathrm{AD}^{13}$.

The cutoff point suggested for evaluation of treatment efficacy is 15 Scorad change, since 11 is considered a normal range fluctuation in $\mathrm{AD}{ }^{11}$. Also, treatment studies should take into account the sensitization of the host, for example to milk allergy ${ }^{11}$.

The group also suggests the identification of PAD as dependent or independent IgE beyond the definition of severity. Probiotics must meet the criteria of the European Union for research: Human origin; Non-pathogenic behavior even in immunocompromised patients; Resistant to technological processes; Resistant to gastric acid and bile; Adherent to the intestinal epithelium and persistent for some period in gut; Able to produce antimicrobial substances and modulate immune system; Able to influence on metabolic activities"1.

Other confounding factors in probiotics researches are the use of topical corticosteroids, elimination diets, and antibiotic use concomitantly. So a twoweek washout period is suggested ${ }^{11}$. Yang et al. ${ }^{5}$ say that fermented foods should also be excluded from studies to avoid confounding factors. Betsi et al. ${ }^{14}$ indicate SCORAD should be assessed by two physicians independently to reduce bias.

\section{CONCLUSIONS}

We describe here a case of evident response to the use of probiotics in a girl with severe $\mathrm{AD}$, with significant change in severity scores of atopic dermatitis (BSA/SCORAD/FDLQI).

$\mathrm{AD}$ has a complex multifactorial pathogenesis pathway. Modulation of the intestinal microbiota with probiotics may offer a way to prevent or treat allergic diseases such as AD.

We have the informed consent of the parents.

\section{RESUMO}

A dermatite atópica é uma doença de pele comum. O aumento da incidência mudou o foco da pesquisa em dermatite atópica para epidemiologia, prevenção e tratamento. Evidências sugerem que a microbiota intestinal desempenha um papel importante na patogênese da dermatite atópica, induzindo imunossupressão, mas o mecanismo exato ainda não está claro. Os probióticos foram amplamente divulgados para atuar no sistema imunológico. Eles são microrganismos vivos com efeitos imunomoduladores que estimulam as citocinas Th1 e suprimem a resposta Th2 que vem sendo pesquisada para o tratamento de diversas doenças. Probióticos mais comumente usados são parte da microflora intestinal como lactobacilos, bifidobactérias e enterococos. Descrevemos um caso de resposta evidente ao uso de probióticos em uma menina com dermatite atópica grave, com grande alteração nos escores de gravidade da dermatite atópica (BSA/Scorad/FDLQI). A modulação da microbiota intestinal com probióticos pode oferecer uma maneira de prevenir ou tratar doenças alérgicas, incluindo a dermatite atópica. 


\section{REFERENCES}

1. Caramia G. Probiotics: from Metchnikoff to the current preventive and therapeutic possibilities. Pediatr Med Chir. 2004;26(1):19-33

2. Savilahti E. Probiotics in the treatment and prevention of allergies in children. Biosci Microflora. 2011;30(4):119-28.

3. Oranje AP. Evidence-based pharmacological treatment of atopic dermatitis: an expert opinion and new expectations. Indian J Dermatol. 2014;59(2):140-2.

4. Wang IJ, Wang JY. Children with atopic dermatitis show clinical improvement after Lactobacillus exposure. Clin Exp Allergy. 2015;45(4):779-87.

5. Yang HJ, Min TK, Lee HW, Pyun BY. Efficacy of probiotic therapy on atopic dermatitis in children: a randomized, double-blind, placebo-controlled trial. Allergy Asthma Immunol Res. 2014;6(3):208-15.

6. Baquerizo Nole KL, Yim E, Keri JE. Probiotics and prebiotics in dermatology. J Am Acad Dermatol. 2014;71(4):814-21.

7. Matsumoto M, Ebata T, Hirooka J, Hosoya R, Inoue N, Itami S, et al. Antipruritic effects of the probiotic strain LKM512 in adults with atopic dermatitis. Ann Allergy Asthma Immunol. 2014;113(2):209-16.e7.

8. Kumar S, Mahajan BB, Kamra N. Future perspective of probiotics in dermatology: an old wine in new bottle. Dermatol Online J. 2014;20(9).
9. Allen SJ, Jordan S, Storey M, Thornton CA, Gravenor MB, Garaiova I, et al. Probiotics in the prevention of eczema: a randomised controlled trial. Arch Dis Child. 2014;99(11):1014-9.

10. ji GE. Probiotics in primary prevention of atopic dermatitis. Forum Nutr. 2009;61:117-28.

11. Lee J, Seto D, Bielory L. Meta-analysis of clinical trials of probiotics for prevention and treatment of pediatric atopic dermatitis. J Allergy Clin Immunol. 2008;121(1):116-21.e11.

12. Panduru M, Panduru NM, Sălăvăstru CM, Tiplica GS. Probiotics and primary prevention of atopic dermatitis: a meta-analysis of randomized controlled studies. I Eur Acad Dermatol Venereol. 2015;29(2):232-42

13. Michail SK, Stolfi A, Johnson T, Onady GM. Efficacy of probiotics in the treatment of pediatric atopic dermatitis: a meta-analysis of randomized controlled trials. Ann Allergy Asthma Immunol. 2008;101(5):508-16

14. Betsi Gl1, Papadavid E, Falagas ME. Probiotics for the treatment or prevention of atopic dermatitis: a review of the evidence from randomized controlled trials. Am J Clin Dermatol. 2008;9(2):93-103. 